\title{
Editorial
}

\section{Bullying: mais uma epidemia invisível?}

\section{Bullying: another invisible epidemic?}

Marisa Palácios ${ }^{1}$

Sergio Rego ${ }^{2}$

Foi divulgado, em 2003, o relatório de uma pesquisa multicêntrica internacional, realizada sob os auspícios da Organização Internacional do Trabalho, sobre a violência nos ambientes de trabalho no setor saúde ${ }^{1}$. Este estudo foi realizado em países com diferentes graus de desenvolvimento socioeconômico: Brasil, África do Sul, Bulgária, Tailândia, Líbano, Portugal e Austrália. A idéia era quantificar e qualificar o fenômeno da violência nesses ambientes. No Brasil, o estudo foi realizado na cidade do Rio de Janeiro ${ }^{2}$. Entre as grandes surpresas evidenciadas pelos estudos, encontra-se a violência perpetrada contra profissionais de saúde por profissionais de saúde. A violência entre colegas. A violência entre chefes e subordinados. Embora a violência física também tenha sido observada, foi a violência moral, denominada assédio moral, a que mais chamou a atenção da equipe. Ela "refere-se a um comportamento ofensivo, humilhante, que desqualifica ou desmoraliza, repetido e em excesso, através de ataques vingativos, cruéis e maliciosos que objetivam rebaixar um indivíduo ou grupo de trabalhadoras/es"2.

Um dos fatos que ajudou a dar destaque à violência entre estes atores foi observado num dos locais pesquisados. Uma pesquisadora foi procurada por um profissional de nível superior que não havia sido selecionado na amostra para ser entrevistado e ele, chorando, agradeceu que alguém estivesse preocupado com a violência que assume a forma do assédio moral. Dizia ele: "esta prática faz com que a gente acabe quase acreditando no que dizem da gente, de tanto que a pressão e as humilhações se repetem". Este fenômeno, o assédio moral, vem ganhando espaço na literatura especializada e na grande imprensa em geral e tem nomes específicos em inglês: mobbing e moral harassment. $\mathrm{O}$ assédio moral não tem nada a ver com uma administração rigorosa ou exigente, mas tem a ver, cada vez mais, com uma forma perversa de administrar que tem sido, assustadoramente, tolerada.

Se refletirmos um pouco mais amplamente, veremos que tal fenômeno não é exclusivo dos ambientes de trabalho. Hoje, cada vez mais, tal prática vem sendo denunciada e mais ações têm sido realizadas para coibi-la nas escolas de primeiro e segundo graus. É o bullying - termo que tem sido utilizado para designar uma prática perversa de humilhações sistemáticas de crianças e adolescentes no ambiente escolar. Tem sido, inclusive, objeto de política explícita de combate em estabelecimentos de ensino. A dimensão do problema pode ser identificada, por exemplo, com a quantidade de comunidades virtuais no Orkut que vêm tratando do tema, incentivando a constituição de redes de proteção e apoio. Assustadoramente, porém, também se encontram comunidades de incentivo ao bullying e à violência no trote.

O bullying pode ser identificado por meio de algumas ações, como ressalta a Abrapia ${ }^{3}$ : "colocar apelidos, ofender, zoar, gozar, encarnar, sacanear, humilhar, fazer sofrer, discriminar, excluir, isolar, ignorar, intimidar, perseguir, assediar, aterrorizar, amedrontar, tiranizar, dominar, agredir, bater, chutar, empurrar, ferir, roubar, quebrar pertences". Estudo realizado por essa associação em 2002 mostrou, em pesquisa realizada em 11 escolas no Rio de Janeiro com alunos da $5^{\text {a }}$ à $8^{\text {a }}$ série, que $16,9 \%$ dos alunos foram vítimas de bullying, 10,9\% foram vítimas e autores, e $12,7 \%$ foram somente autores no último ano. 
Entre a escola, em especial de ensino médio, e o ambiente de trabalho há o espaço da formação profissional e - a que aqui nos interessa particularmente - a formação médica. Já se observa certa preocupação com as causas e conseqüências do bullying nas escolas, assim como com o assédio moral nos ambientes de trabalho. Por que não atentarmos para o problema deste tipo de violência em nossas escolas médicas? E o que temos feito para combater o bullying?

É inegável que existe um grande esforço em muitas escolas para combater o trote violento, especialmente após os trágicos acontecimentos ocorridos na virada do século. Da mesma forma, são louváveis e também contribuem para o apoio ao estudante os serviços de apoio psicológico e educacional que se multiplicam em várias escolas. Mas será que o problema está sendo adequadamente considerado apenas com esse tipo de intervenção? Decerto que não. Em primeiro lugar, o bullying é um tema praticamente ausente nas discussões em nossos congressos e em nossa revista, sugerindo que o que falta inicialmente é reconhecer o problema como um problema ou ao menos disseminar essa percepção. É verdade que temos falado com alguma freqüência do trote, mas ainda parece haver um longo caminho a percorrer.

Pensar no bullying ou assédio moral na escola médica é ter que incluir não apenas o espaço educacional propriamente dito, mas também o espaço de trabalho, em decorrência da integração existente entre esses espaços. Logo, não podemos nos ater apenas ao tradicional entendimento de bullying como um problema estudantil. É preciso focar também o problema do assédio moral, típico dos ambientes de trabalho - onde a relação entre professor e aluno passa também a ser considerada. Estudos realizados em outros países demonstram a freqüência e a relevância do problema ${ }^{4-8}$. Um estudo realizado pela British Medical Association - Medical Students Committee ${ }^{9}$ revelou dados particularmente preocupantes: um terço dos estudantes entrevistados sofreram o bullying; um em cada quatro foram vitimados por um(a) médico(a), e um em cada seis por enfermeiro(a). As formas de bullying compreenderam desde discriminação racial e sexual a humilhações na frente de pacientes, não excluindo as que ocorreram em salas de cirurgia. No Brasil, analisando a percepção de problemas morais por estudantes de medicina, Rego obteve depoimentos de estudantes que apontavam esta prática no cotidiano das escolas, como o de que "existem professores que gostam de sacanear os alunos" e "existem professores que são grosseiros e não respeitam os alunos"10.

Não se pretende, neste editorial, colocar sobre os professores a responsabilidade por todo bullying que ocorre nas escolas, mas assinalar com clareza que o bullying não é apenas um problema dos alunos e nem o resultado natural da competição. É necessário que a Escola Médica tenha uma posição muito clara de enfrentamento deste problema, contribuindo para romper a espiral de violência que se reproduz ano após ano e mesmo entre gerações. É preciso que os valores morais que a escola considera significativos para a formação profissional não sejam apenas apontados estritamente para o momento da relação profissional-paciente. É preciso que a formação moral seja de fato uma preocupação da escola e que seja implementada uma política de tolerância zero com o bullying, o assédio moral e qualquer outro tipo de violência, venha de onde vier. Os atores sociais que têm que estar envolvidos incluem tanto as direções de faculdades de medicina e diretores de hospitais e dos demais espaços de ensino, como diretórios acadêmicos, associações de docentes e sindicatos, entre outros. Não é, nem pode ser, tarefa de apenas um grupo social, mas de todos.

\section{REFERÊNCIAS}

1. Martino, V. Workplace violence in the health sector Country case studies Brazil, Bulgaria, Lebanon, Portugal, South Africa, Thailand and an additional Australian study -Synthesis report. The International Labour Office (ILO), the International Council of Nurses (ICN), the World Health Organization (WHO) and Public Services International (PSI) 2002-Workplace violence in the health sector. Disponivel em http://www.icn.ch/ SynthesisReportWorkplaceViolenceHealthSector.pdf International Council of Nurses 2003.

2. Palacios M, Santos ML, Val MB et al. Workplace Violence in the Health Care Sector - Country Case Study Brazil. Geneva, Switzerland: WHO, 2003

3. Abrapia - Associação Brasileira de Proteção à Infância e Adolescência 2006. Programa de redução do comportamento agressivo entre estudantes. Disponível em www.bullying.com.br Consultado em 27 de março de 2006.

4. Daugherty SR, Baldwin DC, Jr, Rowley BD. Learning, satisfaction, and mistreatment during medical internship. JAMA 1998;279:1194-9.

5. Kassebaum DG, Cutler ER. On the culture of student abuse in medical school. Acad Med 1998;73:1149-58.

6. Bjorkqvist K, Osterman K, Hjelt-Back M. Aggression among university'employees. Aggressive Behaviour 1994;20:173-84.

7. Lempp H The hidden curriculum in undergraduate medical education: qualitative study of medical students' perceptions of teaching. BMJ 2004; 329 (7469): 770-3. 
8. Rajput M BMJ.com rapid responses for Lemp and Seale 329 (7469): 770-3. Graduate medical students more likely to recognize humiliation tactics. 7 de dezembro de 2004 . Disponível em bmj.bmjjournals.comcgi/eltters/329/ $7469 / 770$.

9. Medical News Today One in three medical students has been bullied, BMA survey shows. Disponível em $\mathrm{w} w \mathrm{w}$. m e d i c a $1 \mathrm{n}$ e w s t o d a y. c o m / medicalnews.php?newsid $=32836$
10. Rego S. A formação ética dos médicos: saindo da adolescência com a vida (dos outros) nas mãos. Rio de Janeiro: Editora Fiocruz; 2005. p 142-144.

\section{Endereço para correspondência}

Marisa Palácios

Núcleo de Estudos de Saúde Coletiva da UFRJ Praça da Prefeitura da Cidade Universitária Av. Brigadeiro Tromposki, s/no

CEP: 21949-900 - Rio de Janeiro - RJ palacios@nesc.ufrj.br 